\title{
Intra-MRI extraction of diagnostic electrocardiograms using dynamic feedback from carotidal magnetohydrodynamic voltages
}

\author{
Thomas S Gregory ${ }^{1 *}$, Kevin J Wu' ${ }^{1}$, Ehud J Schmidt ${ }^{2}$, John Oshinski ${ }^{3}$, Zion T Tse ${ }^{1}$ \\ From 19th Annual SCMR Scientific Sessions \\ Los Angeles, CA, USA. 27-30 January 2016
}

\section{Background}

During Cardiac Magnetic Resonance Imaging (CMR), blood plasma electrolytes ejected into the aorta during early systole interact with the static magnetic field of the MR scanner $\left(\mathrm{B}_{0}\right)$ to produce a Magnetohydrodynamic (MHD) Effect [1]. Electrocardiograms (ECGs) recorded in the presence of $\mathrm{B}_{0}$ are overlaid with induced MHD voltages $\left(\mathrm{V}_{\mathrm{MHD}}\right)$, leading to non-robustly synchronized imaging [2], and preventing reliable physiological monitoring inside the MRI [3]. Previous methods have sought to separate between $\mathrm{V}_{\mathrm{MHD}}$ and the true ECG $\left(E C G_{\text {real }}\right)$ through adaptive filtering [3], independent component analysis [4], and advanced computational models [5]. However, these methods are based on a static model, which has limited accuracy during varying-rate heart-beats. We aim to develop accurate $\mathrm{ECG}_{\text {real }}$ extraction, as well as real-time Stroke Volume (SV) estimation (proportional to the integral of MHD over systole) [6], with the advantage of physiological feedback through the real-time monitoring of common carotidal MHD, through which the previously static MHD template can be dynamically updated, providing an increased level of accuracy during variations in heart rate, and a continuous estimation of $V_{M H D}$ and $E C G_{\text {real }}$, for the patient's entire duration inside the MRI.

\section{Methods}

12-lead ECGs were acquired in two $(n=2)$ healthy volunteers during 20-second breath-holds in a 3T MRI (Figure 1ab) with the heart at isocenter. A secondary monitor was used to acquire a single anterior-posterior bipolar lead placed approximately on the left common

${ }^{1}$ College of Engineering, University of Georgia, Athens, GA, USA

Full list of author information is available at the end of the article carotid artery (Figure 1c). ECGs were acquired inside $\left(E_{C G_{\text {real }}}+\mathrm{V}_{\mathrm{MHD}}\right)$ and outside $\left(\mathrm{ECG}_{\text {real }}\right)$ the MRI bore during an initial phase in which a static MHD template was extracted, based on lead subtraction. Carotidal MHD was extracted from the single bipolar lead and phase-compensated to match $\mathrm{V}_{\mathrm{MHD}}$ obtained from the 12-lead ECG. Carotid MHD was subsequently used to adaptively train a Least Mean Squares filter (Figure 1d) to update the MHD template and produce: (1) clean 12-lead ECGs; and (2) an accurate SV estimate [6] (Figure 1e).

\section{Results}

The adaptive filtering method was shown to reduce $\mathrm{V}_{\mathrm{MHD}}$ in the acquired 12-lead ECGs, with residual noise forming $<5 \%$ of the R-wave amplitude. The method preserved the true $\mathrm{S}-\mathrm{T}$ segment, while requiring only a short training phase for the 12-lead ECG (10-15 seconds). The Pearson's Correlation Coefficient between Aortic and Carotid MHD increased from 0.51 to 0.88 after the adaptive filtering routine was applied. Figure $1 \mathrm{f}$ shows the extracted 12-lead ECG acquired inside the MRI bore after the training phase.

\section{Conclusions}

A method to extract true sinus rhythm beats from intraMRI 12-lead ECGs was presented and shown to provide accurate dynamic measurements of induced $\mathrm{V}_{\mathrm{MHD}}$ using Carotid artery MHD and ECG real $_{\text {to }}$ allow for advanced physiological monitoring inside the MRI.

\section{Authors' details}

${ }^{1}$ College of Engineering, University of Georgia, Athens, GA, USA. ${ }^{2}$ Radiology, Brigham and Women's Hospital, Boston, MA, USA. ${ }^{3}$ Radiology, Emory University Hospital, Atlanta, GA, USA. 


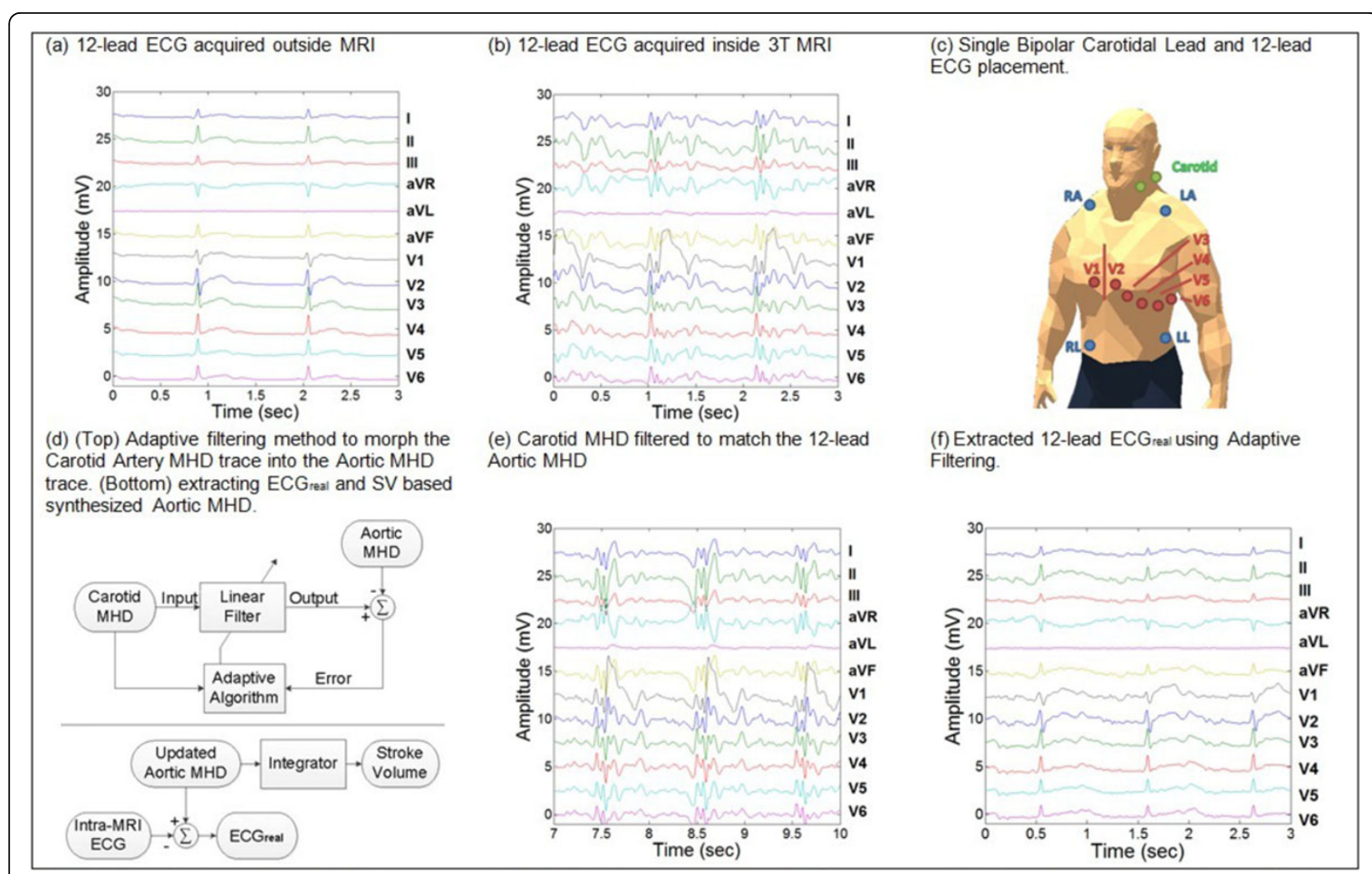

Figure 1 Active removal of induced Magnetohydrodynamic voltages in ECGs recorded inside a 3T MRI using adaptive filtering.

Published: 27 January 2016

\section{References}

1. Gupta: IEEE Trans BioMed Eng 2008.

2. Gregory: MRM 2014

3. Tse: MRM 2013.

4. Krug: Comp Card 2012.

5. Oster: Comp Method Biomed 2014.

6. Gregory: JCMR 2015

doi:10.1186/1532-429X-18-S1-P214

Cite this article as: Gregory et al:: Intra-MRl extraction of diagnostic

electrocardiograms using dynamic feedback from carotidal

magnetohydrodynamic voltages. Journal of Cardiovascular Magnetic Resonance 2016 18(Suppl 1):P214.

Submit your next manuscript to BioMed Central and take full advantage of:

- Convenient online submission

- Thorough peer review

- No space constraints or color figure charges

- Immediate publication on acceptance

- Inclusion in PubMed, CAS, Scopus and Google Scholar

- Research which is freely available for redistribution 